\section{Concurrent determinants of blood pressure among adolescents: the 11-year follow-up of the 1993 Pelotas (Brazil) birth cohort study}

\author{
Determinantes contemporâneos da pressão arterial \\ em adolescentes: a visita de 11 anos da coorte \\ de nascimentos de Pelotas, Rio Grande do Sul, \\ Brasil, 1993
}

\begin{abstract}
1 Programa de Pósgraduação em Epidemiologia Universidade Federal de Pelotas, Pelotas, Brasil. 2 Programa de Pós-graduação em Educação Física, Universidade Federal de Pelotas, Pelotas, Brasil. 3 Faculdade de Nutrição, Universidade Federal de Pelotas, Pelotas, Brasil. 4 Programa de Pós-graduação em Saúde e Comportamento, Universidade Católica de Pelotas, Pelotas, Brasil.

Correspondence A. M. B. Menezes Programa de Pós-graduação em Epidemiologia, Universidade Federal de Pelotas.

Rua Marechal Deodoro 1160, Pelotas, RS 96020-220, Brasil. anamene@terra.com.br

The aim of this study was to evaluate concurrent risk factors for high blood pressure in adolescents. This is a prospective cohort study including 4,452 adolescents born in Pelotas, Rio Grande do Sul State, Brazil, in 1993. Blood pressure was measured before and after the interview, and the mean value was used in the analyses. Mean systolic blood pressure was $101.9 \mathrm{mmHg}(S D=12.3)$ and mean diastolic pressure was $63.4 \mathrm{mmHg}(\mathrm{SD}=$ 9.9). Adolescents with black skin had higher blood pressure than those with white skin. Mean systolic pressure among subjects in the top quartile of body mass index (BMI) was 11.6mmHg higher than among those in the lowest quartile. Mean systolic pressure among postmenarcheal girls was $5.4 \mathrm{mmHg}$ higher than among premenarcheal girls. Similar trends were found for diastolic arterial pressure. Our findings suggest that blood pressure control must begin already in childhood and adolescence.
\end{abstract}

Blood Pressure; Adolescent; Cohort Studies
Ana M. B. Menezes 1

Pedro C. Hallal 1,2

Cora Luiza Araújo 1,3

Fernando C. Barros 4

Cesar G. Victora ${ }^{1}$

\section{Introduction}

High blood pressure during childhood and adolescence is an important risk factor for arterial hypertension in adult life, which in its turn is associated with cardiovascular disease 1,2 . In this context, the World Health Organization (WHO) underscores the importance of the periodic and routine measurement of arterial pressure in children and adolescents as a strategy to reduce morbidity and mortality in adult life 3 .

Risk factors for high blood pressure among adolescents have been evaluated in a number of publications. Authors have highlighted the associations between menarche and arterial pressure 4,5 , and physical activity and body mass index (BMI) ${ }^{6}$. There is also an extensive body of literature investigating the effects of skin color and race on blood pressure that suggests that individuals with dark skin have higher arterial pressure than those with fair skin 7,8,9.

The aim of the present analysis is to evaluate concurrent risk factors associated with high blood pressure among adolescents from the 1993 birth cohort carried out in the city of Pelotas, Southern Brazil. This analysis specifically explores the effects of skin color, BMI, physical activity, and menarche on blood pressure in early adolescence. Early determinants of this variable were reported in a previous publication 10 . 


\section{Methods}

All hospital births taken place in the city of Pelotas in 1993 were monitored. We administered a questionnaire to mothers and weighed and measured their newborn babies. Subsamples of this cohort were visited at ages 1,3 , and 6 months and 1, 4, 6, and 9 years of age. In 2004-2005 all participants of the cohort were traced in a further follow-up study, the details of which have been published elsewhere 11 .

Arterial pressure was measured on the adolescent's wrist using a digital monitor (Omron, Beijing, China) with an error margin of $3 \mathrm{~mm} / \mathrm{Hg}$. Measurements were taken immediately before and after the interview (with an interval of approximately 60 minutes). Measurements were taken with the subject seated. The mean of the two measurements was used for the present analysis. A previous study has found this digital monitor to be easy to use and to produce results that are very similar to those of a mercury sphygmomanometer 12 .

The adolescent's BMI was calculated based on two measurements of weight and height, the mean value of which was used in the analysis. Weight was measured using a digital scale with $100 \mathrm{~g}$ precision (SECA, Birmingham, UK). Height was measured using an aluminum stadiometer with $1 \mathrm{~mm}$ precision. We chose to divide the BMI variable into quartiles. The same procedure was applied to a physical activity score based on a questionnaire that included means of transportation to school and participation in sports or structured or non-structured physical activity inside or outside school. Self-reported skin color was used in all analyses. We chose to evaluate the "black" category (pretos/negros) separately from the "mixed" category (pardos/mulatos), given that the literature suggests a specific effect of African descent on arterial pressure. Menarche was evaluated as a dichotomous variable (yes/ no). An assets index was constructed based on the ownership of domestic goods, using principal component analysis. This index was classified into quintiles for analysis purposes.

We included the following confounders in the analysis: smoking, alcohol intake, family history of hypertension (father or mother), weight and length at birth, gestational age, maternal pre-gestational BMI, and maternal smoking during pregnancy. In addition, we also obtained information on the habit of adding salt to food after serving. However, this variable was not associated with arterial pressure, and was thus excluded from the analyses.

The descriptive analysis included calculating means and standard deviations (SD) for contin- uous variables and percentages for categorical variables. The percentage of hypertensives was calculated based on the cutoff points described in the Fourth Report on the Diagnosis, Evaluation and Treatment of High Blood Pressure in Children and Adolescents 13 (percentile > 95 according to sex, age, and height). We then carried out Pearson correlation analyses for systolic and diastolic arterial pressure, BMI, and physical activity score. In crude analysis, we compared mean arterial pressure between the subgroups defined by the independent variables, using the $\mathrm{T}$ test for menarche and analysis of variance for the remaining independent variables. In adjusted analysis, in addition to adjusting for confounders, we used a hierarchical model for entering independent variables into the model. The five independent variables were hierarchized into three levels. The first level included only skin color. The second included the assets index, and the third included BMI, physical activity score, and menarche.

The present study was approved by the Research Ethics Committee of the School of Medicine, Federal University in Pelotas. Parents or caretakers signed a term of free informed consent authorizing the youth to participate in the study.

\section{Results}

Of the 5,249 participants of the cohort, 4,452 were traced at the 11-year follow-up. When added to the 141 known to have died before this age, traced subjects represented $87.5 \%$ of the original cohort. Among those interviewed at 11 years, $67 \%$ were white, $23 \%$ were at risk of overweight or obesity, and only $42 \%$ reached the recommended level of 300 minutes per week of physical activity.

Mean systolic arterial pressure among adolescents was $101.9 \mathrm{mmHg}$ ( $\mathrm{SD}=12.3$ ), being slightly higher $(\mathrm{p}=0.08)$ among boys $(102.2 \pm 12.2 \mathrm{mmHg})$ when compared to girls $(101.5 \pm 12.5 \mathrm{mmHg})$. Mean diastolic pressure was $63.4 \mathrm{mmHg}$ (SD = $9.9)$, and was also slightly higher $(\mathrm{p}=0.12)$ among boys $(63.5 \pm 9.8 \mathrm{mmHg})$ than among girls $(63.1 \pm$ $9.9 \mathrm{mmHg}$ ). The correlation coefficient between systolic and diastolic pressure was 0.78 . Based on the cutoff points of the Fourth Report on the Diagnosis, Evaluation and Treatment of High Blood Pressure in Children and Adolescents 13, prevalence of arterial hypertension was $7 \%$ among boys and $7.2 \%$ among girls.

Table 1 presents the mean values of systolic pressure according to the five independent variables for the whole sample and for each sex in separate. Youths with white skin had slightly lower levels of systolic pressure when compared 
Mean and standard deviation (SD) of systolic arterial pressure according to skin color, body mass index (BMI) and physical activity score for the total sample and for boys and girls separately. 1993 Pelotas (Brazil) birth cohort, 2004-2005 follow-up.

\begin{tabular}{|c|c|c|c|c|c|c|}
\hline \multirow[t]{2}{*}{ Variables } & \multicolumn{2}{|c|}{ Total sample } & \multicolumn{2}{|c|}{ Boys } & \multicolumn{2}{|c|}{ Girls } \\
\hline & Mean (SD) & p-value * & Mean (SD) & $\mathrm{p}$-value * & Mean (SD) & p-value * \\
\hline Self-reported skin color & & 0.001 & & 0.21 & & $<0.001$ \\
\hline White & $101.4(12.2)$ & & $101.9(12.1)$ & & $100.8(12.3)$ & \\
\hline Mixed & $103.0(12.2)$ & & $103.8(12.7)$ & & $102.2(11.6)$ & \\
\hline Black & $102.8(12.6)$ & & $102.6(12.2)$ & & $103.0(12.9)$ & \\
\hline Assets index (quintiles) & & 0.002 & & 0.003 & & 0.03 \\
\hline 1st (poorest) & $102.3(13.0)$ & & $101.9(12.8)$ & & $102.8(13.1)$ & \\
\hline $2^{\text {nd }}$ & $100.4(11.8)$ & & $100.2(11.5)$ & & $100.5(12.1)$ & \\
\hline $3 \mathrm{rd}$ & $102.2(12.3)$ & & $102.8(12.1)$ & & $101.8(12.4)$ & \\
\hline $4^{\text {th }}$ & $102.5(12.5)$ & & $103.2(12.3)$ & & $101.9(12.6)$ & \\
\hline $5^{\text {th }}$ (richest) & 101.7 (11.9) & & 102.9 (11.9) & & 100.5 (11.9) & \\
\hline BMI (quartiles) & & $<0.001$ & & $<0.001$ & & $<0.001$ \\
\hline 1st (lowest) & $96.9(11.5)$ & & $97.8(11.7)$ & & $96.1(11.2)$ & \\
\hline $2^{\text {nd }}$ & $99.7(11.2)$ & & $99.7(11.2)$ & & $99.6(11.3)$ & \\
\hline 3 rd & $102.6(11.1)$ & & $103.1(11.0)$ & & $102.1(11.3)$ & \\
\hline 4th (highest) & $108.3(12.4)$ & & $108.4(12.0)$ & & $108.2(12.7)$ & \\
\hline Physical activity score (quartiles) & & 0.03 & & 0.03 & & 0.12 \\
\hline 1st (least active) & $102.1(12.3)$ & & $103.1(11.9)$ & & $101.5(12.5)$ & \\
\hline $2^{\text {nd }}$ & $102.6(12.8)$ & & $102.7(12.5)$ & & $102.5(13.0)$ & \\
\hline 3 rd & $101.5(12.5)$ & & $102.2(12.6)$ & & $100.7(12.3)$ & \\
\hline $4^{\text {th }}$ (most active) & $101.1(11.6)$ & & $101.0(11.5)$ & & $101.2(11.8)$ & \\
\hline Menarche & & & & & & $<0.001$ \\
\hline No & - & & - & & $100.6(12.3)$ & \\
\hline Yes & - & & - & & $106.1(12.5)$ & \\
\hline
\end{tabular}

BMI: body mass index.

* $p$-values calculated using $t$ test for menarche and analysis of variance for the other independent variables.

to those with black or mixed skin, but this difference was not statistically significant among boys. There was a significant association between the assets index and systolic arterial pressure in both the total sample and for each sex. However, there was no dose-response relationship between these two variables. BMI was directly and significantly associated with systolic arterial pressure, with a difference between extreme quartiles of $11.4 \mathrm{mmHg}$ for the total sample, $10.6 \mathrm{mmHg}$ among boys, and $10.1 \mathrm{mmHg}$ among girls. The Pearson correlation coefficient for systolic arterial pressure and BMI was $0.37(\mathrm{p}<0,001)$. For diastolic pressure, this value was $0.29(\mathrm{p}<0.001)$.

Physical activity was significantly associated with systolic pressure in the total sample and among boys. In both cases, systolic pressure was lower in the fourth (most active) quartile, though differences were moderate. Using the physical activity score as a continuous variable yielded Pearson correlation coefficients for systolic and diastolic pressure of $-0.02(\mathrm{p}=0.15)$ and -0.02 $(\mathrm{p}=0.11)$, respectively. Menarche was strongly associated with systolic arterial pressure.

Table 2 presents mean diastolic arterial pressure according to independent variables. The association between skin color and diastolic pressure was very similar to that skin color and systolic pressure - i.e., white adolescents had lower pressure levels - but this association was not significant among boys. Once again, the association between assets index and arterial pressure showed no clear dose-response trend. BMI was positively and significantly associated with the outcome in all analyses, the difference between extreme quartiles being of $7.1 \mathrm{mmHg}$ for the total sample, $6.0 \mathrm{mmHg}$ among boys, and $8.0 \mathrm{mmHg}$ among girls. As in the case of systolic pressure, a large difference was found between the two lowest and the two highest BMI quartiles. The association between diastolic pressure and physical activity was also of moderate magnitude. The 
Mean and standard deviation (SD) of diastolic arterial pressure according to skin color, body mass index (BMI) and physical activity score for the total sample and for boys and girls separately. 1993 Pelotas (Brazil) birth cohort, 2004-2005 follow-up.

\begin{tabular}{|c|c|c|c|c|c|c|}
\hline \multirow[t]{2}{*}{ Variables } & \multicolumn{2}{|c|}{ Total sample } & \multicolumn{2}{|c|}{ Boys } & \multicolumn{2}{|c|}{ Girls } \\
\hline & Mean (SD) & $\mathrm{p}$-value * & Mean (SD) & p-value * & Mean (SD) & $\mathrm{p}$-value * \\
\hline Self-reported skin color & & $<0.001$ & & 0.30 & & $<0.001$ \\
\hline White & $62.9(9.7)$ & & $63.4(9.8)$ & & $62.5(9.5)$ & \\
\hline Mixed & $63.6(9.8)$ & & $64.0(10.3)$ & & $63.2(9.3)$ & \\
\hline Black & $64.3(10.2)$ & & $64.1(9.9)$ & & $64.6(10.5)$ & \\
\hline Assets index (quintiles) & & 0.006 & & 0.10 & & 0.05 \\
\hline 1 st (poorest) & $63.8(10.7)$ & & $63.6(10.5)$ & & $64.0(11.0)$ & \\
\hline $2^{\text {nd }}$ & $62.5(9.7)$ & & $62.6(9.5)$ & & $62.4(9.9)$ & \\
\hline 3 rd & $63.6(9.6)$ & & $64.1(9.6)$ & & $63.2(9.6)$ & \\
\hline $4^{\text {th }}$ & $64.0(9.7)$ & & $64.3(9.7)$ & & $63.7(9.8)$ & \\
\hline 5th (richest) & $62.9(9.3)$ & & $63.4(9.4)$ & & $62.4(9.1)$ & \\
\hline BMI (quartiles) & & $<0.001$ & & $<0.001$ & & $<0.001$ \\
\hline 1st (lowest) & $60.4(9.5)$ & & $61.1(9.6)$ & & $59.8(9.3)$ & \\
\hline $2^{\text {nd }}$ & $61.9(9.4)$ & & $62.1(9.4)$ & & $61.7(9.3)$ & \\
\hline 3 rd & $63.6(9.3)$ & & $64.1(9.4)$ & & $63.1(9.2)$ & \\
\hline 4th (highest) & $67.5(9.9)$ & & $67.1(9.8)$ & & $67.8(9.9)$ & \\
\hline Physical activity score (quartiles) & & 0.006 & & 0.03 & & 0.03 \\
\hline 1st (least active) & $63.4(10.2)$ & & $63.9(10.3)$ & & $63.1(10.2)$ & \\
\hline 2 nd & $64.0(10.3)$ & & $64.2(10.2)$ & & $63.9(10.4)$ & \\
\hline 3 rd & $63.0(9.9)$ & & $63.6(10.2)$ & & $62.2(9.5)$ & \\
\hline $4^{\text {th }}$ (most active) & $62.6(8.9)$ & & $62.6(8.7)$ & & $62.6(9.1)$ & \\
\hline Menarche & & & & & & $<0.001$ \\
\hline No & - & & - & & $62.6(9.8)$ & \\
\hline Yes & - & & - & & $66.1(10.0)$ & \\
\hline
\end{tabular}

BMI: body mass index.

* $p$-values calculated using $t$ test for menarche and analysis of variance for the other independent variables.

strong positive association with age of menarche was also detected for diastolic pressure.

Table 3 presents the results of linear regression for systolic arterial pressure. Black and mixed adolescents showed similar coefficients among themselves, and higher pressure levels than white adolescents, although these associations were stronger for black adolescents due to higher numbers. Adjusted analysis confirmed the significant association, but without a doseresponse effect, between assets index and arterial pressure. The direct association with BMI was confirmed in adjusted analysis, with those in the highest quartile showing a mean systolic pressure $11.6 \mathrm{mmHg}$ higher than those in the lowest quartile. The weak association with physical activity was confirmed in adjusted analysis, though these results were significant only for the total sample and among girls. The second quartile of physical activity showed the highest value of systolic pressure among girls, whereas among boys the highest value was found in the first quartile. Mean systolic pressure among postmenarcheal girls was $5.4 \mathrm{mmHg}$ higher than among the premenarcheal group.

Table 4 presents the results of multivariate analysis for diastolic arterial pressure. Black adolescents showed a diastolic pressure almost $2.0 \mathrm{mmHg}$ higher than that of white adolescents. Once again there was a significant association, though lacking a dose-response effect, between arterial pressure and assets index in the total sample. This association was not evident among either girls or boys separately. The positive association with BMI was confirmed after adjustment in all groups. Regarding physical activity, the second quartile consistently showed higher diastolic pressure, and magnitude of the associations remained moderate. Postmenarcheal girls had a mean diastolic pressure $3.6 \mathrm{mmHg}$ higher than premenarcheal girls. 
Linear regression coefficients $(95 \%$ confidence interval - 95\% Cl) for systolic arterial pressure according to independent variables for the total sample and for boys and girls separately. 1993 Pelotas (Brazil) birth cohort, 2004-2005 follow-up.

\begin{tabular}{|c|c|c|c|c|c|c|}
\hline \multirow[t]{2}{*}{ Variables * } & \multicolumn{2}{|c|}{ Total sample } & \multicolumn{2}{|l|}{ Boys } & \multicolumn{2}{|l|}{ Girls } \\
\hline & Coefficient $(95 \% \mathrm{Cl})$ & p-value & Coefficient $(95 \% \mathrm{Cl})$ & p-value & Coefficient $(95 \% \mathrm{Cl})$ & $\mathrm{p}$-value \\
\hline Self-reported skin color & & 0.001 & & 0.21 & & $<0.001$ \\
\hline White & 1.00 & & 1.00 & & 1.00 & \\
\hline Mixed & $1.63(-0.10 ; 3.36)$ & & $1.91(-0.53 ; 4.35)$ & & $1.39(-1.06 ; 3.83)$ & \\
\hline Black & $1.42(0.61 ; 2.23)$ & & $0.64(-0.52 ; 1.81)$ & & $2.17(1.03 ; 3.31)$ & \\
\hline Assets index (quintiles) & & 0.001 & & $<0.001$ & & 0.09 \\
\hline 1st (poorest) & 1.00 & & 1.00 & & 1.00 & \\
\hline 2nd & $-1.84(-3.01 ;-0.67)$ & & $-1.54(-3.18 ; 0.09)$ & & $-2.15(-3.83 ;-0.48)$ & \\
\hline $3 r d$ & $0.11(-1.06 ; 1.29)$ & & $1.10(-0.56 ; 2.76)$ & & $-0.81(-2.48 ; 0.86)$ & \\
\hline $4^{\text {th }}$ & $0.49(-0.69 ; 1.67)$ & & $1.60(-0.05 ; 3.24)$ & & $-0.59(-2.27 ; 1.10)$ & \\
\hline 5th (richest) & $-0.07(-1.28 ; 1.13)$ & & $1.47(-0.18 ; 3.13)$ & & $-1.67(-3.41 ; 0.08)$ & \\
\hline BMI (quartiles) & & $<0.001$ & & $<0.001$ & & $<0.001$ \\
\hline 1st (lowest) & 1.00 & & 1.00 & & 1.00 & \\
\hline 2nd & $3.62(2.14 ; 5.11)$ & & $1.79(0.33 ; 3.26)$ & & $3.81(2.33 ; 5.28)$ & \\
\hline 3 rd & $5.54(4.03 ; 7.06)$ & & $5.20(3.70 ; 6.69)$ & & $6.08(4.60 ; 7.56)$ & \\
\hline $4^{\text {th }}$ (highest) & $11.58(10.03 ; 13.13)$ & & $10.74(9.19 ; 12.29)$ & & $12.35(10.86 ; 13.84)$ & \\
\hline Physical activity score (quartiles) & & 0.03 & & 0.07 & & 0.02 \\
\hline 1st (least active) & 1.00 & & 1.00 & & 1.00 & \\
\hline 2nd & $1.19(-0.15 ; 2.53)$ & & $-0.15(-1.79 ; 1.50)$ & & $1.11(-0.23 ; 2.45)$ & \\
\hline 3 rd & $-0.87(-2.27 ; 0.53)$ & & $-0.44(-2.01 ; 1.12)$ & & $-0.90(-2.30 ; 0.51)$ & \\
\hline 4th (most active) & $-0.52(-2.06 ;-1.02)$ & & $-1.68(-3.19 ;-0.16)$ & & $-0.60(-2.14 ; 0.94)$ & \\
\hline Menarche & & & & & & $<0.001$ \\
\hline No & - & & - & & 1.00 & \\
\hline Yes & - & & - & & $5.36(3.97 ; 6.75)$ & \\
\hline
\end{tabular}

BMI: body mass index.

* Adjusted for smoking, alcohol intake, weight and length at birth, gestational age, mother's pre-gestational body mass index, reported maternal or paternal hypertension, and smoking during pregnancy. In addition, BMI, physical activity score, and menarche were adjusted for skin color and assets index, whereas the reverse adjustment was not performed.

\section{Discussion}

This is one of the few Brazilian studies to evaluate arterial blood pressure among adolescents in a population-based sample. Prevalence of hypertension in the sample - close to $7 \%$ - is similar to that detected in other Brazilian studies $14,15,16,17,18,19$. The age range in these studies was 6 to 18 years, and prevalence of hypertension ranged from $5 \%$ to $16.6 \%$.

The study of arterial pressure becomes even more relevant if we consider that systolic and diastolic pressure levels have been rising among children and adolescents in a number of countries 20 . An analysis of surveys conducted in the United States between 1963 and 2002 showed that the arterial pressure of children and adolescents decreased between 1963 and 1988, after which it began to increase 20 .
There is no data on trends in arterial pressure among Brazilian adolescents. However, given the increase in prevalence of obesity 21 , it is reasonable to assume that a similar increase in blood pressure is also taking place in our settings.

Our results show a strong association between blood pressure and BMI, in addition to important effects of menarche and skin color on blood pressure. There was no clear dose-response relationship between physical activity and blood pressure.

The international literature provides convincing evidence that Blacks have higher levels of arterial pressure than Whites 7,8,9. Both in the total sample and in analyses separated by sex, blood pressure was higher among adolescents with black skin, diastolic arterial pressure among black girls being on average $2 \mathrm{mmHg}$ higher than among white girls. Potential mechanisms for this 
Linear regression coefficients $(95 \%$ confidence interval $-95 \% \mathrm{Cl})$ for arterial arterial pressure according to independent variables for the total sample and for boys and girls separately. 1993 Pelotas (Brazil) birth cohort, 2004-2005 follow-up.

\begin{tabular}{|c|c|c|c|c|c|c|}
\hline \multirow[t]{2}{*}{ Variables * } & \multicolumn{2}{|c|}{ Total sample } & \multicolumn{2}{|l|}{ Boys } & \multicolumn{2}{|l|}{ Girls } \\
\hline & Coefficient $(95 \% \mathrm{Cl})$ & $p$-value & Coefficient $(95 \% \mathrm{Cl})$ & p-value & Coefficient $(95 \% \mathrm{Cl})$ & $p$-value \\
\hline Self-reported skin color & & $<0.001$ & & 0.30 & & $<0.001$ \\
\hline White & 1.00 & & 1.00 & & 1.00 & \\
\hline Mixed & $0.67(-0.72 ; 2.05)$ & & $0.65(-1.32 ; 2.62)$ & & $0.70(-1.23 ; 2.64)$ & \\
\hline Black & $1.43(0.78 ; 2.09)$ & & $0.71(-0.23 ; 1.65)$ & & $2.12(1.23 ; 3.02)$ & \\
\hline Assets index (quintiles) & & 0.008 & & 0.06 & & 0.15 \\
\hline 1st (poorest) & 1.00 & & 1.00 & & 1.00 & \\
\hline 2nd & $-1.15(-2.08 ;-0.21)$ & & $-0.91(-2.22 ; 0.41)$ & & $-1.36(-2.69 ;-0.03)$ & \\
\hline 3 rd & $0.08(-0.85 ; 1.02)$ & & $0.72(-0.61 ; 2.05)$ & & $-0.48(-1.80 ; 0.84)$ & \\
\hline $4^{\text {th }}$ & $0.53(-0.41 ; 1.47)$ & & $0.97(-0.36 ; 2.29)$ & & $0.12(-1.21 ; 1.45)$ & \\
\hline 5 th (richest) & $-0.36(-1.32 ; 0.60)$ & & $0.17(-1.17 ; 1.50)$ & & $-0.89(-2.27 ; 0.49)$ & \\
\hline BMI (quartiles) & & $<0.001$ & & $<0.001$ & & $<0.001$ \\
\hline 1st (lowest) & 1.00 & & 1.00 & & 1.00 & \\
\hline 2 nd & $1.99(0.78 ; 3.19)$ & & $0.88(-0.31 ; 2.08)$ & & $2.10(0.91 ; 3.30)$ & \\
\hline 3 rd & $2.93(1.70 ; 4.16)$ & & $2.91(1.69 ; 4.13)$ & & $3.33(2.13 ; 4.52)$ & \\
\hline 4th (highest) & $7.67(6.41 ; 8.93)$ & & $6.07(4.80 ; 7.34)$ & & $8.22(7.02 ; 9.43)$ & \\
\hline Physical activity score (quartiles) & & 0.02 & & 0.04 & & 0.03 \\
\hline 1st (least active) & 1.00 & & 1.00 & & 1.00 & \\
\hline 2nd & $0.61(-0.47 ; 1.70)$ & & $0.64(-0.70 ; 1.99)$ & & $0.54(-0.54 ; 1.63)$ & \\
\hline 3 rd & $-1.14(-2.28 ; 0.00)$ & & $0.20(-1.08 ; 1.47)$ & & $-1.17(-2.30 ;-0.03)$ & \\
\hline $4^{\text {th }}$ (most active) & $-0.75(-2.00 ;-0.50)$ & & $-0.98(-2.22 ; 0.25)$ & & $-0.82(-2.07 ; 0.43)$ & \\
\hline Menarche & & & & & & $<0.001$ \\
\hline No & - & & - & & 1.00 & \\
\hline Yes & - & & - & & $3.57(2.46 ; 4.69)$ & \\
\hline
\end{tabular}

BMI: body mass index.

* Adjusted for smoking, alcohol intake, weight and length at birth, gestational age, mother's pre-gestational body mass index, reported maternal or paternal hypertension, and smoking during pregnancy. In addition, BMI, physical activity score, and menarche were adjusted for skin color and assets index, whereas the reverse adjustment was not performed.

association include less efficient excretion of sodium and fluids by Blacks, which would lead to a greater tendency to concentrate urine, and consequently greater susceptibility to hypertension 7. Unlike most other health outcomes, the association between arterial pressure and skin color does not seem to be explainable by socioeconomic level, since adjustment for this variable did not affect the association between skin color and arterial pressure in the present study.

BMI showed the strongest association with blood pressure among all variables included in the analysis. Among girls, mean systolic pressure was $12 \mathrm{mmHg}$ higher in the uppermost quartile when compared to the lowest. A review study has shown that risk of developing arterial hypertension among obese children is three times higher than among the non-obese 22 .
The absence of a linear association between physical activity and arterial pressure among adolescents is in agreement with a systematic review of the literature that concluded that there is no conclusive evidence for an association between these variables during adolescence 6 . A previous cross-sectional study carried out in Brazil 16 also failed to detect an association between blood pressure and physical activity among children and adolescents. Despite the absence of a linear trend, our results show that adolescents with lower physical activity scores had higher arterial pressure in both sexes. Prospective analyses will be required to investigate this association longitudinally.

Postmenarcheal girls showed the highest levels of arterial pressure. An analysis of the Guangzhou cohort study in China showed that girls whose menarche had occurred earlier were at 
higher risk of hypertension 4 . An analysis of the Fels cohort in the United States also confirmed that earlier menarche was associated with higher arterial pressure 5 . Although earlier menarche is associated with body composition 23 , the association between menarche and blood pressure was not affected by adjustment for BMI.

Effective strategies for controlling arterial pressure are necessary already during childhood and adolescence. In a previous publication, we showed that a number of early-life factors were associated with blood pressure in adolescence 10 . In the present article, we evaluate the association between blood pressureand concurrent variables. Future analyses using data from this same cohort will be able to determine the extent to which high blood pressure in adolescence is related to hypertension and other morbidities in adult life.

\section{Resumo}

O objetivo do presente artigo foi avaliar fatores associados com a pressão arterial de adolescentes. Trata-se de estudo de coorte prospectivo, incluindo 4.452 adolescentes nascidos em Pelotas, Rio Grande do Sul, Brasil, em 1993. A pressão arterial foi medida no início e final da entrevista com aparelho digital, sendo o valor médio utilizado nas análises. A pressão arterial sistólica média foi de 101,9mmHg (DP =12,3) e a diastólica foi de $63,4 \mathrm{mmHg}(\mathrm{DP}=9,9)$. Adolescentes com pele preta apresentaram valores mais elevados de pressão arterial sistólica do que os de pele branca. Adolescentes no quartil superior do índice de massa corporal (IMC) apresentaram uma pressão sistólica média 11,6mm $\mathrm{mg}$ maior do que aqueles no quartil inferior. Meninas que já menstruaram apresentaram uma pressão sistólica média 5,4mmHg maior em comparação às demais. Os resultados foram similares para a pressão arterial diastólica. O controle da pressão arterial elevada deve ser iniciado desde a infância e adolescência.

Pressão Arterial; Adolescente; Estudos de Coortes

\section{Contributors}

A. M. B. Menezes coordinate the 1993 birth cohort and led the writing of the manuscript. P. C. Hallal led the data analysis, and approved the final version of the manuscript. C. L. Araújo and F. C. Barros coordinated the 1993 birth cohort and approved the final version of the manuscript. C. G. Victora coordinates all of the birth cohorts and approved the final version of the manuscript.

\section{Acknowledgments}

The cohort study is supported by the Wellcome Trust. The initial stages of the cohort study were supported by the European Union, the Brazilian National Program for Centers of Excellence (PRONEX), the National Research Council (CNPq), and the Brazilian Ministry of Health. 


\section{References}

1. Leitschuh M, Cupples LA, Kannel W, Gagnon D Chobanian A. High-normal blood pressure progression to hypertension in the Framingham Heart Study. Hypertension 1991; 17:22-7.

2. Sytkowski PA, D'Agostino RB, Belanger AJ, Kannel WB. Secular trends in long-term sustained hypertension, long-term treatment, and cardiovascular mortality: the Framingham Heart Study 1950 to 1990. Circulation 1996; 93:697-703.

3. World Health Organization. The World Health Report 2002: reducing risks, promoting healthy life. Geneva: Word Health Organization; 2002.

4. Heys M, Schooling CM, Jiang C, Cowling BJ, Lao X, Zhang W, et al. Age of menarche and the metabolic syndrome in China. Epidemiology 2007; 18:740-6.

5. Remsberg KE, Demerath EW, Schubert CM, Chumlea WC, Sun SS, Siervogel RM. Early menarche and the development of cardiovascular disease risk factors in adolescent girls: the Fels Longitudinal Study. J Clin Endocrinol Metab 2005; 90:2718-24.

6. Twisk JW. Physical activity guidelines for children and adolescents: a critical review. Sports Med 2001; 31:617-27.

7. Bankir L, Perucca J, Weinberger MH. Ethnic differences in urine concentration: possible relationship to blood pressure. Clin J Am Soc Nephrol 2007; 2:304-12.

8. McNiece KL, Poffenbarger TS, Turner JL, Franco KD, Sorof JM, Portman RJ. Prevalence of hypertension and pre-hypertension among adolescents. J Pediatr 2007; 150:640-4, 644.e1.

9. Moore WE, Stephens A, Wilson T, Wilson W, Eichner JE. Body mass index and blood pressure screening in a rural public school system: the Healthy Kids Project. Prev Chronic Dis 2006; 3:A114.

10. Menezes AM, Hallal PC, Horta BL, Araújo CL, Vieira MF, Neutzling M, et al. Size at birth and blood pressure in early adolescence: a prospective birth cohort study. Am J Epidemiol 2007; 165:611-6.

11. Araújo CL, Menezes AMB, Vieira MFA, Neutzling MB, Gonçalves H, Anselmi L, et al. The 11-year followup of the 1993 Pelotas (Brazil) birth cohort study: methods. Cad Saúde Pública 2010; 26:1875-86

12. Plavnik FL, Zanella MT. Validation study of an automated wrist monitor, omron model HEM-608, compared with the standard methods for blood pressure measurement. Arq Bras Cardiol 2001; 77:532-40
13. US Department of Health and Human Services The fourth report on the diagnosis, evaluation and treatment of high blood pressure in children and adolescents. Washington DC: US Department of Health and Human Services; 2005.

14. Rodrigues AN, Moyses MR, Bissoli NS, Pires JG, Abreu GR. Cardiovascular risk factors in a population of Brazilian schoolchildren. Braz J Med Biol Res 2006; 39:1637-42.

15. Rosa MLG, Fonseca VM, Oigman G, Mesquita ET. Pré-hipertensão arterial e pressão de pulso aumentada em adolescentes: prevalência e fatores associados. Arq Bras Cardiol 2006; 87:46-53.

16. Monego ET, Jardim PCBV. Determinantes de risco para doenças cardiovasculares em escolares. Arq Bras Cardiol 2006; 87:37-45.

17. Silva MAM, Rivera IR, Ferraz MRTM, Pinheiro AJT, Alves SWS, Moura AA, et al. Prevalência de fatores de risco cardiovascular em crianças e adolescentes da rede de ensino da cidade de Maceió. Arq Bras Cardiol 2005; 84:387-92.

18. Oliveira RG, Lamounier JA, Oliveira ADB, Castro MDR, Oliveira JS. Pressão arterial em escolares e adolescentes: o estudo de Belo Horizonte. J Pediatr (Rio J.) 1999; 75:256-66.

19. Rezende DF, Scarpelli RA, Souza GF, Costa JO, Scarpelli AM, Scarpelli PA, et al. Prevalence of systemic hypertension in students aged 7 to 14 years in the municipality of Barbacena, in the State of Minas Gerais, in 1999. Arq Bras Cardiol 2003; 81:381-6.

20. Din-Dzietham R, Liu Y, Bielo MV, Shamsa F. High blood pressure trends in children and adolescents in national surveys, 1963 to 2002. Circulation 2007; 116:1488-96.

21. Monteiro CA. Trends in the burden of disease due to under- and over-nutrition in the developing world. Forum Nutr 2003; 56:266-7.

22. Sorof J, Daniels S. Obesity hypertension in children: a problem of epidemic proportions. Hypertension 2002; 40:441-7.

23. Sherar LB, Baxter-Jones AD, Mirwald RL. The relationship between body composition and onset of menarche. Ann Hum Biol 2007; 34:673-7.

Submitted on $03 / \mathrm{Feb} / 2009$

Final version resubmitted on 11/Aug/2009

Approved on 03/Sep/2009 